HOME ABOUT LOGIN REgISTER ETHICS CURRENT ISSUE ARCHIVE

CURRENT ISSUE

Home > Archives > No 2 (2016)

No 2 (2016)

\section{Education Sciences \& Society - Alignment, attunement, co-} activity, co-regulation. Convergent trajectories?

\section{Table of Contents}

\section{Editorial/Editoriale}

Alignment, attunement, co-activity, co-regulation: convergent trajectories?

VIEW OR DOWNLOAD PDF Michele Corsi, Pier Giuseppe Rossi, Vladimir Megdeved

\section{Articles}

Apprendimento e Insegnamento nella prospettiva dell'Enattivismo

PDF (ITALIANO)

Elio Damiano

Alignment

VIEW OR DOWNLOAD PDF

Pier Giuseppe Rossi

The non-linear potential of didactic action

Maurizio Sibilio, Iolanda Zollo

Start a community of practice through Action Learning: nurse manager to support the changing care practices

Stefano Bonometti

Integrated school-community projects to promote motor activity through possible alignment with professionals

Antinea Ambretti, Antonio Borgogni, Rodolfo Vastola, Simone Di Gennaro,

Vladimir Medved, Francesca D'Elia

Motor technique and didactics: a possible alliance from an educational point of view

Carmen Palumbo, Susana Franco, Ferdinando Cereda

I processi inclusivi nella prima infanzia tra diritti e responsabilità

Roberta Caldin

School-family-community collaborations: the contribution of the

intercultural worker in accompanying newly immigrant parents to school

Josée Charette, Jean-Claude Kalubi

Organizations' choices when implementing an Early Intensive Behavioral

Intervention program (EIBI)

Carmen Dionne, Jacques Joly, Annie Paquet, Myriam Rousseau, Mélina Rivard

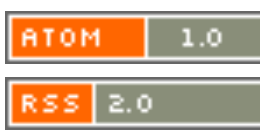

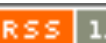

USER

Username

Password

Remember me

Login

NOTIFICATIONS

- View

- Subscribe

\section{KEYWORDS}

Convention U.N. on the of Persons with Disabilitie Didactic corporealities Didactic morphologies Didactic postures Early Intensive Behavioral Intervention Linearity National Observatory on Status of Persons with Disabilities Physical educ Program implementation Simplexity childhood constructionism didactics educational services emp enaction learning phenomenology primary school school projects teaching

VIEW OR DOWNLOAD PDF

JOURNAL CONT

Search

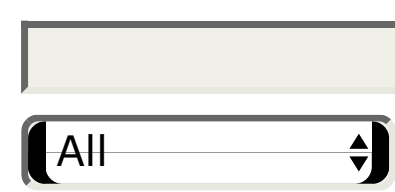

Search

\section{Browse}

- By Issue

- By Author

- By Title

- Other Journal

FONT SIZE

[Ai] $A$ AA]

Education Sciences \& Society - Open Access Peer Reviewed Journa ISSN 2038-9442 | AUT. TRIB. MILANO N. 80 DEL 13/07/2016

This journal applies the Creative Commons Attribution - Non-Commercial - No Derivatives (CC BY-NC-ND) license to works published, in order to facilitate free immediate access to, and unrestricted reuse of original works of all types. Under this license, authors agree to make articles legally available for reuse, without permission or fees, for virtually any purpose. Anyone may copy, distribute or reuse these articles, without modifying them, as long as authors and original sources are properly cited.
INFORMATION

- For Readers

- For Authors

- For Librarian 


\title{
Integrated school-community projects to promote motor activity through possible alignment with professionals
}

\author{
Antinea Ambretti', Antonio Borgogni2, Rodolfo Vastola ${ }^{3}$, Simone Di Gennaro', \\ Vladimir Medved ${ }^{5}$, Francesca D'Elia ${ }^{6}$
}

In the context of primary school motor activities, it is not uncommon that the educational relationship is at least trialectic (Eichberg, 2010), that is it responds to a plurality of educators whose interaction and synergy entails significant repercussions on the teaching efficacy, and, ultimately, on the quality of education. The plurality of the persons involved can become a resource, if the participation organization is truly integrated, thought and handled with reference to the children's educational needs.

Since the ' $70 \mathrm{~s}$ - even though the regulatory framework has changed motor education in primary school - after its name has been changed from elementary school to primary school, and the application of national indications, rather than national programs - has always maintained a hybrid status, with a strong territorial connotation.

At least for a certain period, and especially in certain regions, the most significant experiences referred to the idea of the integrated education system (Frabboni, 1988; Frabboni and Guerra, 1991).

Since the end of the last century, territorial hybridisation has allowed to develop significant and long-lasting experiences, often funded by Local Bodies and by the School, sometimes co-funded by families, and, lastly, by private individuals. Without aiming to give an exhaustive list, and citing only the relevant pilot projects known to us, let us recall the projects of Prato,

${ }^{1}$ Antinea Ambretti is the author of the article, PHD in Methodology of Educational Research, Contract Professor at the University of Salerno, ssd MEDf/01cdl, Faculty of Primary Education "Laboratory of Motor Activity Methods and Didactics".

2 Antonio Borgogni, coauthor of the article, Scholar ssd MEDf/01at the University of Cassino, Faculty of Human Sciences, physical activity society.

${ }^{3}$ Rodolfo Vastola Scholar ssd MEDf/01 at the University of Salerno cdl; he has cooperated to the definition of the sports expert role in a school environment.

${ }^{4}$ Simone Di Gennaro research assistant ssd MEDF/01 at the University of Cassino, Faculty of Human Sciences, physical activity society; he has cooperated to drafting the section concerning the motor literacy projects.

${ }^{5}$ Vladimir Medved Director of the motor analysis laboratory, and professor Kinesiology at the University of Zagreb; he has cooperated to drafting the section concerning the qualitative research data evaluation.

${ }^{6}$ Francesca D'Elia associate professor ssd MEDF/01 at the University of Salerno; she is the scientific coordinator of the project. 
Casalecchio di Reno, Turin, and, at a later time, the projects of Rimini and Trento. These projects were directly developed with trainers and external teachers, or, in other cases, promoted in cooperation with sports promotion institutions. They all took inspiration from the motor/body educational inadequacy, often self-declared, of female teachers, elucidating integrated territory-school projects in which qualified external educators would hold motor education lessons along with the teaching staff.

The meaning, or rather, the educational intentionality of those projects had a dual purpose: offering quality motor activities to the children and train the female teachers. Training was articulated in two steps: in the first instance, its purpose was to develop the competences of the female teaching staff, so that they could best perform the second weekly hour of activities; in the second instance, this training attempted to supply them a certain educational independence, so that the motor educational activity could continue after the project came to its conclusion.

All these projects involve, in a co-generative logic, a participated planning between external and staff teachers; some of them also included a common theoretical and practical training. In some cases, the practical and actual training was addressed only to female staff teachers, in some other to both types of teachers at the same time, through training courses which became coplanning workshops, facilitating the common planning based on shared body experiences. Often, these projects directly referred to or were supervised by the teachers of the Faculties of Pedagogy and Human Movement Sciences. Some of these have become case or research subjects in Faculties of Primary Education, and, at a later time, in Faculties of Motor Sciences.

Planning was defined together before the start of the school year, when also the motor education and staff teacher training, or self-training, was carried out. In some cases, with the aid of local education authorities, the training experiences became on-going courses.

In the past decade, many of these local projects have continued their course by including the new Motor Science graduates as external teachers.

Some of these projects witnessed an extensive participation by private entities; we mention here the project funded by Barilla, currently called "Giocampus", which, for several years, in the last decade, was extended from Parma to the other provinces of the Emilia-Romagna region. Other projects, fostered by sports promotion institutions, received state funding; we mention here the project, and information campaign, "Diamoci una Mossa", by UISP, focused on an active lifestyle and on a healthy nutrition.

In several areas, there structured and integrated projects were accompanied by detailed actions, not included in this article, where local sports associations, governing bodies and institution, often sponsored by private entities that 
supplied gadgets and materials, were involved with schools to promote their activities. Unfortunately, due to the lack of school resources and specific competences, many of these actions were only episodic, and only partially educational, and, ultimately, even though they were often welcomed, they were not co-planned, as an alternative, by staff teachers.

The diffusion of Memoranda of Understanding between the MIur and Coni, aimed at promoting and improving the diffusion of motor activities in schools, so as to allow a gradual acquisition of skills and competences in the various stages of childhood development, has urged the Ministry to wonder anew about the importance of a ever-growing active involvement of the schools in planning recreational/motor/sports activities aimed at spreading a movement culture in the didactic-educational world.

These elements were then implemented in the National Curricula Instructions for kindergartens and primary schools of 2007, where the respective teachers are instructed on the guidelines to plan the curricula and extracurricular activities focused on the centrality of the child and of its development phases, in terms of psychological and physical well-being, highlighting a strong interest for the body-movement relationship. Thus, it is now asked to the teachers, starting from kindergarten, to plan recreational/ motion courses for the young students, capable of guaranteeing the "functionality of movement articulated in its various forms" (Sibilio, 2001) to foster a construction of their identity, in view of psychological and physical well-being.

In line with these, the latests National Curricula Instructions for kindergartens and primary schools of 2012, required additional competences from the respective teachers, posing themselves as didactic/operative guidelines for the students and for the new teacher training needs. Over the years, the call of the Ministry to an educational liability for kindergarten and primary school teachers, has embodied the need to rethink the essential teacher knowledge; in kindergartens and primary school, the teacher is first and foremost an experimenter who knows "how to guide the child effectively and accurately" (Sibilio, 2001) through a constant and active involvement of various didactic/ heuristic skills.

In particular, the MIUR highlights the involvement of the students, starting in kindergarten, in recreational/motion/sports activities, which require the skills of kindergarten and primary school teachers to include knowledge and skills relating to the sports/motor field, and additionally highlighting the need for the Italian educational field, to guarantee a rigorous theoretical and didactical/ operative preparation on the matter to kindergarten and primary school teachers. 


\section{The "Motor Literacy" National Project}

At the end of the last decade, thanks to a Memorandum of Understanding between the MIUR and CONI, the "Motor Literacy" National Project was implemented, as a shared experimentation phase "within the respective institutional competences [aimed at creating] a motor literacy program to be implemented in primary schools, as a response to the growing alarms by the scientific community and by international institutions on the consequences of a sedentary lifestyle and improper eating and life habits among the youth».

The original project idea then revisited during the project, included two interconnected work programmes:

- a feasibility assessment and project start programme (A.S. 2009/2010), to be carried out on a selected number of sample schools;

- a three-year operative project, aimed, among other things, at experimenting the feasibility of the inclusion of motor activities (and motor activity teachers) in the curricula (2010/2011; 2011/2012; 2012/2013).

The project conclusion included a transition from the four-year project period to the permanent inclusion of a motor activity teacher in the primary schools. The external teacher, referred to as "expert", selected by the schools involved from a list approved by the organizers, was required to carry out the application function of a wide-scope educational/political (according to the definition below) design, shared by the national institutional actors - MIUR and CONI - within a primary school reorganization strategy.

In the first year, the educational activity included two hours per week per class, for part of the school year (total of 30 hours per class), in which the expert was asked to «support the [tenured] teacher - sole person responsible for the class activities [...]» in order to promote the «motor activity [as an] occasion to foster cognitive, social, cultural and affective experiences» (Coni, 2010).

A strong emphasis was given on promoting active lifestyles, with a contingent plan similar to a positive social engineering idea, through which induce changes in daily habits, aimed at achieving an higher well-being for every citizen (in this case, for the student involved in the project) and for the community in general.

The experts, apart from implementing the educational guidelines set forth by the project, were also required, as stated above, to verify/create the conditions to include the motor activities in the primary school curricula.

\section{Relationships within the project and the role of the expert}

The relationship between the expert and the student are part of a much wider relationship network, which, in basic terms, intertwines between the 
entities promoting a project/event (MIUR and CONI, in the case of the Motor Literacy and related projects), the school, the tenant teachers, the students and the parents.

Apart from these actors, in the project in question, there is also the figure of the supervisor in charge of administratively coordinating the project and of guaranteeing the local educational quality of the schools involved.

The existing interconnections influence the relationship between the expert and the student, affecting it in a significant way. The relationship network includes several and various variation factors, difficult to summarize; however, some of them seem to affect the relationship in a more profound way:

- the nature of the Motor Literacy project, whose specifications have changed over time;

- the relationship between tenant teacher and expert;

- the relationship between tenant teacher, project expert and tutor, in charge of coordinating the project;

- the relationship between the school and the expert (many of the experts involved had already cooperated with the schools where they led the ML project).

While carrying out their roles, the experts held a triple function:

- street-level agent, according to the meaning suggested by Lipsky (1969), appointed to implement, at least in the initial project intentions, a mediumterm political strategy (4 years), mainly aimed at experimenting and then implementing a scholastic reorganization, and, at the same time, at mediating between the School and CONI;

- supporting educator for the teaching staff involved in the MIUR primary school guidelines implementation process;

- promotor/operator of active lifestyle promotion policies (especially in the first years of the project).

In the definition developed by Lipsky (1969), street-level agents are those individuals supplying a public service by interacting directly with the citizens (and with intermediate organizations), and operating mostly in context characterized by scarce resources and by a "typical" tension between the pressures binding them "from above" and the needs of the citizens "from below".

In the fulfillment of the first function (street-level) agent, the expert, aided by the supervisor, was asked to solve organizational conflicts and to make decisions, while taking into account the different requests and influences exerted by the actors involved in the project: MIUR and CONI, from above, the school, the teachers and the students, from below. In some instances, the figure of the experts, and thus the role they were asked to fulfill within the school, came under some pressure: interpretation of project specifications, scarcity of resources combined with the school's requests, political indications set 
forth by CONI/MIUR, organizational needs (e.g. schedule) and the assessment of the educational needs to be met have induced the experts to assume contextual operative strategies which significantly affected the project and their relationship with the students involved in the project (the citizens).

The second (educator) and third (promotor/operator) function have significantly affected the relationship with the students. In the first instance, a markedly educational dimension has been established, which has tended to enrich the motor skills of the students, and, in many cases, to use the body as a subject/object of a multidimensional educational practice: cognitive, affective, social, etc. In the second instance, even though not everywhere, some of the experts have included moments for reflections on habits and lifestyles in the activities carried out, contributing to creating, rather than a simple educational cause for reflection, a space focused on sociality, health, well-being, etc. This second approach can be associated to a lifestyle-orientation trainer/trainee relationship, characteristics of many European companies which see the school (and the teachers) as actors capable of preventing deviant behaviours and fostering healthier lifestyles (Simovska e McNamara, 2015).

As detailed in the next paragraph, the project was most effectively applied where it was possible to create a shared sphere of action between tenant teacher-expert-student; within these contexts, the expert intervention and the way in which the student growth has been affected, have been more effective and long-lasting.

In a broader view, it may be argued that, in educational relationships, there is always a variance between the action intention - the project's objectives, for example - and implementation. This variance is due to a series of variables truly difficult to summarize. However, among these variables, the context in which an educational operation is carried out, and the limiter ratio accompanying the actions of the educator (see Digennaro e Borgogni, 2015) seem to have a significant weight.

In the case in question, a further widening of the variance was due to the misalignment levels which were often detected in the School/Coni and Tenant Teacher/Expert relationships, and to the conflicts between the (hierarchical and didactic) authorities involved in the process.

In order to establish a fruitful cooperation between the teacher and the experts, it is essential to establish training courses for both figures, capable of bridge the professional gaps, and aimed at establishing a specific skill portfolio to be implemented in the educational context.

It would be necessary to supply to school teachers a suitable education, in order to make them better of "understand and acknowledge exactly how a movement is carried out (...) so as to adapt its methodological procedures to the instantaneous level of mastery of movement" (Meinel, 1991). 
The sports figures would need to be involved in specific sports/motor activity educational courses, in order to make them better understand "those typical qualities related to the majority of sports/motor activities"(Meinel,1991) in a school environment

The ideal situation of a shared sphere of action has often been impossible to implement, due to the relationship difficulties between the project actors, which have enormously affected the implementation of the activities, thus limiting the expert's grip on the students.

Thus, it would not be a matter of equating figures with different roles and professions, but rather to highlight the need of more professionalized paths for all the figures involved in the educational processes, aiming at a possible alignment between professional roles, not to undermine the specific professionalism of each actor, but rather to highlight their strengths in childhood and preadolescence education and training field; since these figures are present and operating in schools, it would be desirable to revisit both training programs. To this end, Meinel (1991) mentions the alignment between the teacher figure and the coach/educator figure, by defining the combination of the two figures as two "educational possibilities useful to illustrate those motor sensations connected to a correct execution of the movement to be learned by the student" so that each actor "must not be limited to their own subject" (Meinel, 1991)

In this respect, training programs for all teachers and for all educational/ sports operators should have been based mainly on the didactic/educational skills deriving from training programs capable of fostering the educational capacity through motor and sports experiences (D'Elia, Sibilio, 2015).

In formal and informal teacher and tutor training contexts, this would require the establishment of specific programs capable of making the didactic/ educational and social/psychological orientation apparent, and to establish curricula where the specific didactic/motor training is enhanced.

"The analysis of the motor/sports professions entails specific complexity and specificity levels:

- the "dynamic plurality" of meaning that the activities related to each profession assume in the different contexts, creating multiple profiles which, in turn, require specific training capable of adequately meeting the everchanging needs of society, which questions the choices on the competences and qualification procedures of the professionals operating in the amateur and/or professional motor/sports field;

- the self-referentialism of many organizations which, in the Italian Achilles Heel on the matter, have self-imposed themselves as training agents capable of building the professional competences associated to the different profiles;

- the simplification, related to the diffusion of commonplaces due to which, from the athlete or sportsman competences can derive those of motor and 
sports activity professional in the different fields. This reductive vision of the construction of motor/sports skills at different levels translates into the attribution of a sophisticated expertise - generalizable in many other contexts, to sportsman, while overlooking the specific competences and the harmonized integration of knowledge, skills and resources needed to guarantee adequate competences and to plan work projects and specific intervention frameworks in motor activities" (Sibilio e Aiello, 2010).

A possible reflections on the weaknesses and criticalities of the teacher, the tutor and/or of other figures pertaining to the scholastic/sports world, would made the cooperation between these figures more functional, given the fact that "when teachers educate their students through movement, they do not only care about the physical aspects, but also about the entirety of the individual" (Sibilio e D'Elia, 2015).

In defining the recreational/motor and sports/motor national projects, the Ministry has underlined that the primary scope of their experimentation and diffusion in national primary schools is "to spread the physical and sports education since childhood, to foster educational and training processes in younger generations" (MIUR, 2014).

It is not a matter of supplying complete motor competences to the students, but rather transmitting, through the recreational/motor and motor/sports activity, educational messages related to the construction of a personal and social identity, in view of a psychological and physical well-being.

\section{Educational Relationships: Results of a Qualitative Research}

On the occasion of the launch of the Motor Literacy project 2012/13, we conducted a research based on semi-structured questionnaires submitted to some of the project supervisors $(n=8)$. The results were summarized during the training course held for the supervisors coming from the entire national territory, held in Ostia, on December 2012 (Borgogni, 2012).

The supervisors, selected based on their significant experience in this and other projects, were specifically interrogated on the relationship between experts and teaching staff, A wide range of behaviours and attitudes came to light, in which the gradient between alignment and misalignment allowed to speculate, with a sufficient degree of plausibility, the educational repercussions on the children.

From the tenant teacher side, the behaviours were classified in three categories. The first category is characterized by the commitment to a shared construction of new knowledge, aimed at a shared programming to qualify their work and putting themselves on the line, by directly participating to 
the practical part of the lessons. The second category refers to a cautious yet positive position, where the relationship with the expert is envisaged as capable of extending their professionalism and educational intervention. The third category must be interpreted in a negative fashion, and it involves the desire to relieving themselves from work, the lack of willingness to plan the lessons, and the delegation of these tasks to the expert.

The classifications emerging from the expert behaviour analysis are even more interesting. The categories are similar, albeit some differences, and they include a fourth category. A cross-cutting aspect to be considered is that the expert was motivated to participate also for economic reasons. The first category includes the willingly experts who, knowing that they are "stepping into someone else's home", are committed to cooperate. The second category includes the experts who are committed and "plan too many activities", also in reference with the project curricula, and who apply it by the book, running the risk of losing important information and educational opportunities. The third category includes those experts who do not wish to plan with the teachers, because they only "want to practice sports" and are not interested in relating their activities to the curricula. The fourth category includes those experts who think that "they [the teachers] don't understand", and who hope they leave everything in their hands.

The relationship between the expert and the tenant teachers, from the expert standpoint, is highlighten by certain sentences, directly quoted in the supervisor interviews, which deem that the teachers are available to integrate and cooperate "when they see in us not the expert who can suggest "spectacular" exercises, but rather when, in our activities, even when simple, they see the intention of working on all the aspects of the single individual and class group", and when they notice that through the motor activity, we can supply them an additional key to understand both the positive and negative class aspects, and thus to tackle, through our activities, the issues that they have observed in the class.

Furthermore, certain supervisors highlighted the possibility of interaction that the project did not take into account, such as programs or actions to foster the active home-school movement, the aspects related to food education, necessary to foster healthy and active lifestyles, or the significance of motor education in an intercultural perspective, which were often crushed by strict curricula.

Many of the supervisors had held the role of expert in the previous years, in this or other projects, and thus they aimed at a relationship in which the motor activity scope goes beyond the hours assigned, within a relationship, albeit asymmetrical, aimed at a shared program with the teachers.

It is clear how, by reading these relationships thoroughly, it is highly probable that the common educational projects, and the students' experience, 
runs the risk of being fragile, maybe valid as sum of episodic experiences, and, thus, not inferable in view of a sustainable educational and training practice (Borgogni et al., 2010). Where the two actors were aligned, and the environmental conditions favourable, the supervisors nonetheless highlighted the availability and integration of skills by the teachers, which can lead to presume a future continuity.

However, the project did not include any assessment on the processes or on the educational repercussions on children, with particular reference to their lifestyles; it only included a final test aimed at establishing the skills acquired based on the period of time employed to carry out a standardized motor course.

\section{Projects subsequent to Motor Literacy}

At the end of the fourth year of the Motor Literacy Project, after stating the impossibility of implementing and completing the project by including a tenant motor activity teacher, MIUR and CONI have agreed an extension of the cooperation for a bridge project called "Primary School Project" (2013/2014), which has preceded, in the two following academic years (2014/2015 and 2015/2016) the "Class Sport" project. Apart from the changed name, a careful analysis of the specifications of the three projects allows identifying also a substantial culture change, which has significantly affected the role of the expert, and, consequently, the relationship established with the students involved in the project.

Namely, the Primary School Project recalls some of the objectives of the previous project, with the declared intent of "promoting the motor and sports activities at school" (Coni,2013)It was expressly defined as a «transition toward the definition of a new intervention model ${ }^{3} \gg$. It preceded the "Class Sports" project, and a change in direction of the expert function. The expert is now established as "a specialized figure included within the school" (CONI, 2013), appointed to support the school principal and the teachers on the motor and sports activities, through an active cooperation in planning the educational activities, along with operational activities during the school hours.

To this end, the broaden perspective suggested by the SBAM (Sport Benessere Alimentazione e Mobilità) project, funded by the Puglia Region and implemented from 2012/2013 to 2014/2015, thanks to the cooperation of the University of Foggia and of the Coni-Puglia, is highly significant. These institutions were in charge of the project planning, teacher training, project monitoring and recruiting of the experts working with the children. With respect to the cited national projects, SBAM included two additional actions: healthy food habit education and active transport/sustainable mobility education 
(safe house-school-house paths), implemented through the presence of experts graduates in motor sciences, nutritionists and dieticians, which have held integrated lessons and have supported the tenant teachers. The national and SBAM programs have been carried out in many schools of the Puglia region at the same time, thus one schools has hosted both programs (the national and the regional one). The substantial differences with the cited national projects concerned: a more thorough initial training and current training of the expert graduates; motor activity monitoring for three years, concerning the motor capacity, motor ability, psychological constructs (enjoyment)and self-efficacy perceived in children from 8 to 10 years of age (Colella, 2014).

In the emerging perspective, the expert becomes the operator of a (national or regional) policy, and of a cultural change not anymore oriented towards including a motor activity teacher within the school, but rather toward stimulating a reinforcement of the existing school and student competences/resources. Furthermore, the expert is required to be, from a co-planning standpoint, the bridge between school and territory, in a wider cooperative view between all the subjects involved in the student educational and growth processes.

\section{Bibliographical references}

Sibilio M., Aiello P. (2010). The teaching research focused on the movement: heuristic approaches and elements of complexity, Journal of Physical Education and Sport, 29, 4: 52-56.

Borgogni A. (2012). Tra significati e paradossi: la relazione tra educatori. Comunicazione nel convegno "Alfabetizzazione Motoria. Corso nazionale di aggiornamento Supervisori”, Ostia 14-16/12/2012.

Borgogni A., Digennaro S., Manzo S., Vannini E. (2010). Towards Sustainable Didactics. Exercise and Quality of Life, Volume 2/2010: 43-49.

Sibilio M., D’Elia F. (2015). Professionalità in ambito motorio e sportivo. In Cunti, A., a cura di (2015). Corpi in formazione. Voci Pedagogiche. Milano: FrancoAngeli.

Colella D. (2014). Physical education in primary school in Italy. The Sbam! program for the promotion of physically active lifestyles. In Scheuer C., Antala B., Holzweg M. (Eds.), Physical Education: Quality in management and teaching. Berlino: Logos Verlag Berlin GmbH, pp. 121-134.

CONI (2010), Alfabetizzazione motoria nella scuola primaria Indicazioni per l'organizzazione dell'attività motoria nella scuola primaria, Presentazione ai Supervisori, Università di Verona, Facoltà di Scienze Motorie, 22/23/24 gennaio 2010.

CONI (2013), Progetto Primaria, Aggiornamento modello progettuale ed organizzativo in base agli esiti della sperimentazione.

Digennaro S., Borgogni A. (2015). La razionalità limitata delle scelte educative. Encyclopaideia XIX (41): 21-36. 
Eichberg H. (2010). Bodily democracy. Towards a philosophy of sport for all. Abingdon, Oxon \& New York: Routledge.

Frabboni F., a cura di (1988). Un'educazione possibile. Il sistema formativo tra policentrismo e specialismo. Firenze: La Nuova Italia.

Frabboni F., Guerra L., a cura di (1991). La città educativa. Verso un sistema formativo integrato. Bologna: Cappelli.

Lipsky, M. (1969). Toward a theory of street-level bureaucracy. Madison (WI): Institute for Research on Poverty, University of Wisconsin.

Meinel K. (1991). Teoria del movimento: Abbozzo di una teoria della motricità sportiva sotto l'aspetto pedagogico. Roma: Società Stampa Sportiva.

MIUR nota prot.n. 6263 del 3 novembre 2014 "Progetto nazionale Sport di Classe per la scuola primaria - anno scolastico 2014/2015".

Sibilio, M. (2001). Il corpo e il movimento. Napoli: Cuen, p. 176.

Simovska V., McNamara P.M. (2015). Schools for Health and Sustainability. Theory, Research and Practice. Londra: Springer. 